\title{
Medicines and vaccines supply chains challenges in Nigeria: a scoping review
}

\author{
Victory O. Olutuase ${ }^{1 *}$, Chinwe J. Iwu-Jaja ${ }^{2}$, Cynthia P. Akuoko ${ }^{3}$, Emmanuel O. Adewuyi ${ }^{4}$ and Vishnu Khanal ${ }^{5}$
}

\begin{abstract}
Background: Medicines and vaccines supply chains represent critical systems for realising one of the major targets of the United Nations' third Sustainable Development Goals (SDGs) - access to safe, effective, quality, and affordable essential medicines and vaccines, for all. However, evidence suggests the system is confronted with several challenges in many low-medium income countries, including Nigeria. This scoping review aims to summarize the available evidence on the challenges of medicines and vaccines supply chain system in Nigeria.

Results: We searched relevant databases including Scopus and Web of Science for studies published between January 2005 and August 2020 on the challenges associated with medicines and vaccines supply chain systems in Nigeria. Our findings implicate several factors including difficulty with medicines or vaccines selection, procurement, distribution, and inventory management. Others included poor storage infrastructure, financial constraints, insecurity, transportation challenges, inadequate human resources, weak, or poorly implemented policies. These challenges mostly resulted in stock-outs of essential medicines which notably got worsened during the current COVID-19 pandemic.

Conclusion: Our study is a wake-up call on the need to prioritise the critical sector of the supply chain systems for medicines and vaccines in Nigeria. Effective implementation of existing policies, improved security, strengthening of the health system through adequate budgetary allocations, and provision of infrastructure including regular availability of electricity are keys to surmounting the challenges and improving access to medicines or vaccines in Nigeria.
\end{abstract}

\section{Background}

One of the major targets of the United Nations' third Sustainable Development Goals (SDG), is to ensure access to safe, effective, quality, and affordable essential medicines and vaccines, for all [1]. This target is critical to achieving universal healthcare coverage just as effective health product supply chains are indispensable in ensuring access to quality medicines and vaccines [2]. Health product supply chains assure consistent availability of high-quality medicines, vaccines, and health products at health service delivery points in the most cost-effective and timely manner [3]. A functional health

\footnotetext{
*Correspondence: vicolutuase@gmail.com

1 Department of Clinical Pharmacy and Pharmacy Practice, University of Jos, Jos, Nigeria

Full list of author information is available at the end of the article
}

product supply chain system is indeed the backbone of quality healthcare services $[4,5]$. The phenomenon not only guarantees the delivery of appropriate health products to the end-users, but it also ensures that health system planners receive critical information on the need, demand, and consumption of products, thus, contributing to better service delivery $[3,6]$.

The importance of supply chain management is widely acknowledged, however, access to quality essential medicines in developing countries including Nigeria continues to be a challenge $[2,6]$. Challenges associated with medicine supply chain, in Nigeria, have been identified in the literature ranging from poor infrastructure, weak policy or regulatory implementation and quality compromised by substandard or counterfeit medicines [4]. Other challenges such as stock-outs, poor supply chain practices (e.g., poor inventory, poor forecasting, etc.), 
and inadequate human resources, amongst other factors, have been reported [3,7-11]. To mitigate some of these challenges and improve the efficiency of medicines supply chains in Nigeria, some strategies have been implemented including the development of policies and programs such as the National Drug Policy, Nigeria Supply Chain Policy for Pharmaceuticals, National Drug Distribution Guidelines, regulation of human resources development, and engagement of professionals or personnel with relevant skills [12]. Despite these strategies, the supply chain system, in Nigeria, remains weak and inefficient [2].

So far, some studies, aimed at identifying the challenges associated with the supply chain systems for medicines or vaccines, have been conducted in Nigeria [2, 3, 7, 911]. However, to the best of our knowledge, no study has systematically reviewed the challenges either in the form of a scoping or a systematic review. It is important that these challenges are reviewed, pooling all the evidence, to facilitate the development of robust interventions. This study, thus, summarizes available evidence on the challenges of medicines and vaccines supply chain system in Nigeria. The study is aimed at a comprehensive review of challenges often ecountered in medicine and vaccine supply chain systems in the country. Consequently, we have chosen a scoping review, against a systematic review since the latter addresses precise questions, using a more predefined set of outcomes [13]. Also, while medicines and vaccines are both medicinal products that could be used for treatment or prevention of diseases, respectively, the supply chain of vaccines requires cold storage while medicines do not, except for some medications such as insulin. Hence, where appropriate, we have attempted to highlight supply chain challenges that are peculiar to vaccines. Findings in this study contribute to a better understanding of the subject, identify gaps in knowledge for future studies, as well as provide current evidence for policymakers on the challenges of medicines' supply chain systems in Nigeria.

\section{Methods}

This scoping review was conducted following the Joanna Briggs Institute methodology for scoping reviews [14]. We conducted a knowledge synthesis of existing research on the challenges associated with medicines and vaccines supply chains between 2005 and 2020 in Nigeria. This scoping review aims to answer the question of "what are the challenges of medicines and vaccines supply chain systems in Nigeria'?

\section{Search strategy}

The search strategy for this study was decided and documented by VOO and CJI. The search strings were decided and extracted based on some preliminary articles from journals such as the Journal of Pharmaceutical Health Services Research and Vaccine [2, 15]. Searches were conducted in the Scopus and Web of Science (WOS) databases. These databases have large abstracts and citations covering numerous academic publications such as scientific journals, books, and conference proceedings. Moreover, the databases have a rich collection of research output in the field of medicine and health sciences coupled with a dynamic and flexible search engine for retrieving articles.

Since the main aim of this review was to extract empirical evidence on the challenges of medicine and vaccine supply chains in Nigeria, the search strategy was focused on identifying original research publications, reviews of original research, and case studies, and included all publications in these categories, both published or in the press, open or standard access options. We observed a rise in publication on medicine supply chain management from 2005 to 2020 . Using the search terms, the databases were searched by titles, keywords, abstracts, and indexed keywords as shown in Table 1. The search was done in the English language and limited to studies carried out between January 2005 and August 2020. The search strings and keywords in Table 1 were applied first to medicines and subsequently replicated for vaccines. All searches were carried out in August and September 2020 and documented in an Excel workbook. An additional search was conducted in March 2021.

\section{Duplicate Screening}

All bibliographic citations extracted from Scopus were downloaded in a comma-delimited (CSV) format. VOO coordinated the search strategy, combined all CSV files into one file and used the remove duplicate function in Excel to remove 239 duplicates out of a total of 991 downloaded citations. We found a total of 1,844 relevant citations from the Web of Science database. Web of science has the feature of combining search results and removing duplicates. This feature was used to remove 514 duplicates. A total of 2,082 citations (including their titles, journal, year of publication, abstracts, keywords, and authors) was imported into Rayyan, a web-based systematic review software [16] for further duplicate screening and subsequent screening of titles and abstracts based on inclusion and eligibility criteria.

\section{Inclusion and eligibility criteria}

A two-stage screening process was carried out as required by the scoping review methodology set in Joanna Briggs Institute Manual for Evidence Synthesis [17]. Articles that qualified for inclusion focused on 
Table 1 Search strings and keywords

\begin{tabular}{lll}
\hline SN & Variable & Search Items \\
\hline 1 & Medicine supply chain challenges & $\begin{array}{l}\text { Medicine supply Nigeria } \\
\text { Supply chain of medicines Nigeria } \\
\text { Challenges of medicine supply Nigeria }\end{array}$ \\
2 & Medicine selection challenges & Medicine selection Nigeria \\
3 & Challenges of medicine selection Nigeria \\
4 & Medicine Quantification challenges & Medicine quantification Nigeria \\
5 & Medicine Distribution challenges & Challenges of medicine quantification Nigeria \\
& & Medicine procurement Nigeria \\
& Medicine Storage challenges & Challenges of medicine procurement Nigeria \\
7 & & Medicines distribution Nigeria \\
& Challenges of medicine distribution Nigeria
\end{tabular}

Table 2 Inclusion and eligibility criteria for this review

\begin{tabular}{lll}
\hline SN & Criteria & Explanation \\
\hline 1 & Medicine supply chain challenges & The article should focus on medicine supply chain challenges \\
2 & Medicine selection challenges & The article should focus on medicine selection challenges \\
3 & Medicine Quantification challenges & The article should focus on medicine quantification challenges \\
4 & Medicine procurement challenges & The article should focus on medicine procurement challenges \\
5 & Medicine distribution challenges & The article should focus on medicine distribution challenges \\
6 & Medicine storage challenges & The article should focus on medicine storage challenges \\
7 & Medicine inventory challenges & The article should focus on medicine inventory challenges \\
4 & Nigeria & The article should focus on medicine supply chain challenges, medicine selection, procurement, distribution, \\
5 & Study period & storage and inventory management challenges in Nigeria. \\
6 & Study type & The article should cover 2005 and 2020 \\
& supply chain challenges
\end{tabular}

at least one of the two main variables shown in Table 2 . The studies had to be original research, review of original research or case published in English between 2005 and 2020. Conceptual papers describing one or more of the study variables were excluded. We applied the inclusion and eligibility criteria (Table 2), first in the selection of articles for medicines supply chain challenges and subsequently, vaccines supply chain challenges.

\section{Title, abstract and full-text screening}

After screening and removing 459 duplicates via Rayyan, there were 1623 unique articles left for title and abstract screening. To avoid bias, the BLIND-review feature in Rayyan was activated for all authors to conduct an independent review of titles and abstracts based on the inclusion criteria. After this screening, there were initial 45 conflicts. Reviewers met to resolve these conflicts following the simple majority rule of two out of three reviewers. It, therefore, followed that two out of three reviewers' decision on inclusion or exclusion was affirmed. The full texts of 55 screened articles were thereafter attached to the citations already imported into Rayyan and were further reviewed for inclusion. Twenty-eight full texts were found irrelevant to the scoping review questions or objective and were thus excluded (see details in Table 3). Twenty-seven full-text articles were finally included for analysis (see details in Table 4). Through further Google scholar search, one relevant article was found and was included in the final list of 28 
Table 3 Excluded full texts based on eligibility criteria

\begin{tabular}{lll}
\hline SN & Authors & Title \\
\hline 1 & (Millar et al., 2014) & Patterns and predictors of malaria care-seeking
\end{tabular}

1 (Millar et al., 2014)

2 (Unger et al., 2014)

3 (Mangham-jefferies et al., 2014)

4 (Palafox, n.d.)

5 (Obitte et al., 2009)

6 Babalola, Stella and Lawan, Umar

$7 \quad$ Urban, Boris

$8 \quad$ (Karp et al., 2015)

$9 \quad$ (Bassey et al., 2018)

10 (Odume, 2020)

11 (Griswold et al., 2018)

12 (Petersen et al., 2017)

13 (Mangham-jefferies et al., 2015)

14 (Rao et al., 2017)

15 (Wright et al., 2017)

16 (Ward \& Kynvin, 2015)

17 (Molemodile et al., 2017)

(Osadebe et al., 2017)

18 (Hirsh Bar Gai et al., 2018)

19 (Bangura et al., 2020)
Patterns and predictors of malaria care-seeking,
diagnostic testing, and artemisinin-based combination therapy for children under five withfever in Northern Nigeria: a cross-sectional study

Treating diarrhoeal disease in children under five: the global picture

What determines providers'stated preference for the treatment of uncomplicated malaria?

Mapping the private commercial sector distribution chain for antimalarials in six low-income countries in Africa and South East Asia

Survey of drug storage practice in homes, hospitals, and patent medicine stores in Nsukka, Nigeria

Factors predicting BCG

immunization status in northern Nigeria: a

behavioral-ecological perspective

Interventions to increase the distribution of vaccines in Sub-Saharan

Africa: a scoping review

Evaluating the value proposition for improving vaccine

thermostability to increase vaccine impact in low and middle-income countries

The global switch from trivalent oral polio vaccine (tOPV) to bivalent oral polio vaccine (bOPV): facts, experiences and lessons learned from the southsouth zone; Nigeria, April 2016

Taking tuberculosis preventive therapy implementation to national scale: the Nigerian PEPFAR Program experience

Evaluation of Treatment Coverage and Enhanced Mass Drug Administration for Onchocerciasis and Lymphatic Filariasis in Five Local Government Areas Treating Twice Per Year in Edo State, Nigeria

Surveillance for falsified and substandard medicines in Africa and Asia by local organizations using the low-cost GPHF Minilab

Mind the gap: knowledge and practice of provid ers treating uncomplicated malaria at public and mission health facilities, pharmacies and drug stores in Cameroon and Nigeria

Immunization supply chains: Why they matter and how they are changing

Improving isC performance through outsourcing - Considerations for using third-party service providers to increase innovation, capacity, and efficiency

Consumer-focused supply chains: a cross-case comparison of medicine appeal and acceptance in India, Uganda, and Nigeria

Evaluation of a pilot intervention to redesign the decentralised vaccine supply chain system in Nigeria

Assessing Inactivated Polio Vaccine Introduction and Utilization in Kano State, Nigeria, April November 2015

Evaluating scenarios of locations and capacities for vaccine storage in Nigeria

Barriers to Childhood Immunization in Sub-Saharan Africa: A Systematic Review
Year Reason

2014 Irrelevant because it does not focus on medicine supply chain challenges

2014 Irrelevant because the full text does not capture study variables

2014 Irrelevant because the full text does not capture study variables

2014 Irrelevant because the full text does not capture study variables

2020 Irrelevant because the full text does not capture study variables

2009 Irrelevant because the full text does not capture study variables

2019 Irrelevant because the full text does not capture study variables

2018 Irrelevant because the full text does not capture study variables

2018 Irrelevant because the full text does not capture study variables

2020 Irrelevant because the full text does not capture study variables

2018 Irrelevant because the full text does not capture study variables

2017 Irrelevant because the full text does not capture study variables

2015 Irrelevant because the full text does not capture study variables

2017 Irrelevant because the full text does not capture study variables

2017 Irrelevant because the full text does not capture study variables

2015 Irrelevant because the full text does not capture study variables

2017 Irrelevant because the full text does not capture study variables

2017 Irrelevant because the full text does not capture study variables

Irrelevant because the full text does not capture study variables

2020 Irrelevant because the full text does not capture study variables 
Table 3 (continued)

\begin{tabular}{|c|c|c|c|c|}
\hline SN & Authors & Title & Year & Reason \\
\hline 20 & (Daniel \& Oladapo, 2006) & $\begin{array}{l}\text { Default from tuberculosis treatment programme } \\
\text { in Sagamu, Nigeria Default from Tuberculosis } \\
\text { Treatment Programme in Sagamu, Nigeria }\end{array}$ & 2006 & $\begin{array}{l}\text { Irrelevant because the full text does not capture } \\
\text { study variables }\end{array}$ \\
\hline 21 & (Ikoh et al., 2009) & $\begin{array}{l}\text { The influence of "Stock Out" on health-seeking } \\
\text { behaviour of low-income women in Uyo urban, } \\
\text { Akwa Ibom State, Nigeria }\end{array}$ & 2009 & $\begin{array}{l}\text { Irrelevant because the full text does not capture } \\
\text { study variables }\end{array}$ \\
\hline 22 & (Aina et al., 2017) & $\begin{array}{l}\text { Preliminary results from direct-to-facility vaccine } \\
\text { deliveries in Kano, Nigeria }\end{array}$ & 2017 & $\begin{array}{l}\text { Irrelevant because the full text does not capture } \\
\text { study variables }\end{array}$ \\
\hline 23 & (Tougher et al., 2009) & $\begin{array}{l}\text { The private commercial sector distribution chain } \\
\text { for antimalarial drugs in Benin Findings from a } \\
\text { rapid survey }\end{array}$ & 2009 & $\begin{array}{l}\text { Irrelevant because the full text does not capture } \\
\text { study variables }\end{array}$ \\
\hline 24 & (Brien et al., 2018) & Treat the Pain Program Megan & 2018 & $\begin{array}{l}\text { Irrelevant because the full text does not capture } \\
\text { study variables }\end{array}$ \\
\hline 25 & (Monath et al., 2016) & Yellow fever vaccine supply: A possible solution & 2016 & $\begin{array}{l}\text { Irrelevant because the full text does not capture } \\
\text { study variables }\end{array}$ \\
\hline 26 & (Sutter \& Cochi, 2019) & $\begin{array}{l}\text { Inactivated Poliovirus Vaccine Supply Shortage: Is } \\
\text { There Light at the End of the Tunnel? }\end{array}$ & 2019 & Editorial comment \\
\hline 27 & (Oleribe et al., 2017) & $\begin{array}{l}\text { Individual and socioeconomic factors associated } \\
\text { with childhood immunization coverage in Nigeria }\end{array}$ & 2017 & $\begin{array}{l}\text { Irrelevant because the full text does not capture } \\
\text { study variables }\end{array}$ \\
\hline
\end{tabular}

articles for analysis. Figure 1 presents a flow chart of the article selection process in this study.

\section{Data extraction}

Nine articles were allocated to three reviewers (VOO, CJI, and CKA.) each for data extraction. The reviewers extracted the data following the data extraction matrix as suggested in literature [13]. The extracted data included individual studies' characteristics such as author(s), title, year of publication, journal, the focus of the paper, type of paper, methodology, and key findings based on objectives. These extracted data were captured in an Excel spreadsheet and later analyzed both quantitatively and qualitatively to answer the scoping review questions. It should, however, be noted that analyses did not extend to the quality of included articles as this is only a scoping review [13].

\section{Data summary and synthesis}

Microsoft Excel was used to determine frequencies and simple percentages of the data. These were used to describe the nominal data extracted and to provide a summary of the data (see Table 5). Meanwhile, we performed a qualitative analysis of the included articles' key findings via Atlas.ti version 7. One of the authors (VOO) served as the administrator in this instance. The administrator created the project bundle and shared it with the other four authors. After an initial qualitative data analysis of key findings by the administrator, other authors further synthesized additional findings.

\section{Limitations of the methods}

The possibility of missing additional evidence related to this subject is likely as articles published in unaccredited or un-indexed journals, considered predatory, may have been missed from the search strategy.

\section{Results}

Database searches produced a total of 2,835 citations, out of which 27 articles were included in this review (see Figure 1 and Table 4). Analysis of the general characteristics of included articles (see Table 5) shows that about 68 per cent $(n=19)$ of the articles were published between 2016 and 2020. The remaining articles were published between 2005 and 2015 ( $n=9,32 \%)$. Most of the reviewed papers were original research articles $(n=25,89 \%)$. Also, 79 per cent of the articles were published in international journals such as 'Research in Social and Administrative Pharmacy', and 'Vaccine'. Fifty per cent of the articles focused on Medicine supply challenges $(\mathrm{n}=14$ while the remaining $50 \%$ focused on vaccine supply challenges $(n=14)$.

The frequency for the number of articles reporting each challenge was calculated (see Table 6). Issues relating to medicines or vaccines stockouts topped the list of challenges. Eighteen per cent of the articles $(n=8)$ highlighted these challenges on stockouts, while 14 per cent of the articles $(n=6)$ reported on human resource challenges, storage challenges and technical issues respectively. Eleven per cent of the articles $(n=5)$ further reported on financial challenges, transportation and distributions challenges, policies, and SOPs challenges respectively. Issues on poor data management of medicines and vaccines supply were the least reported ( $7 \%, \mathrm{n}=3$ articles). 


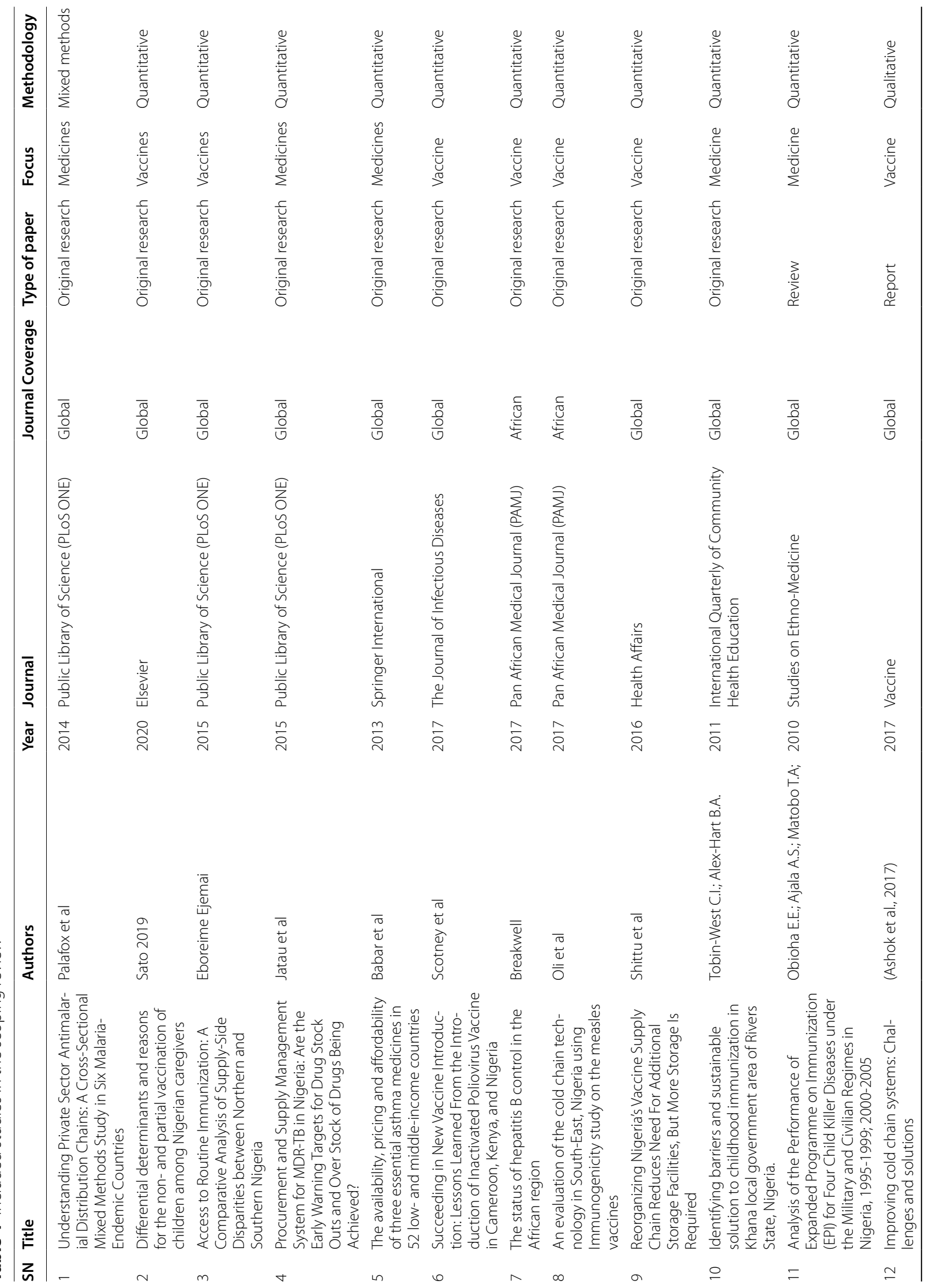




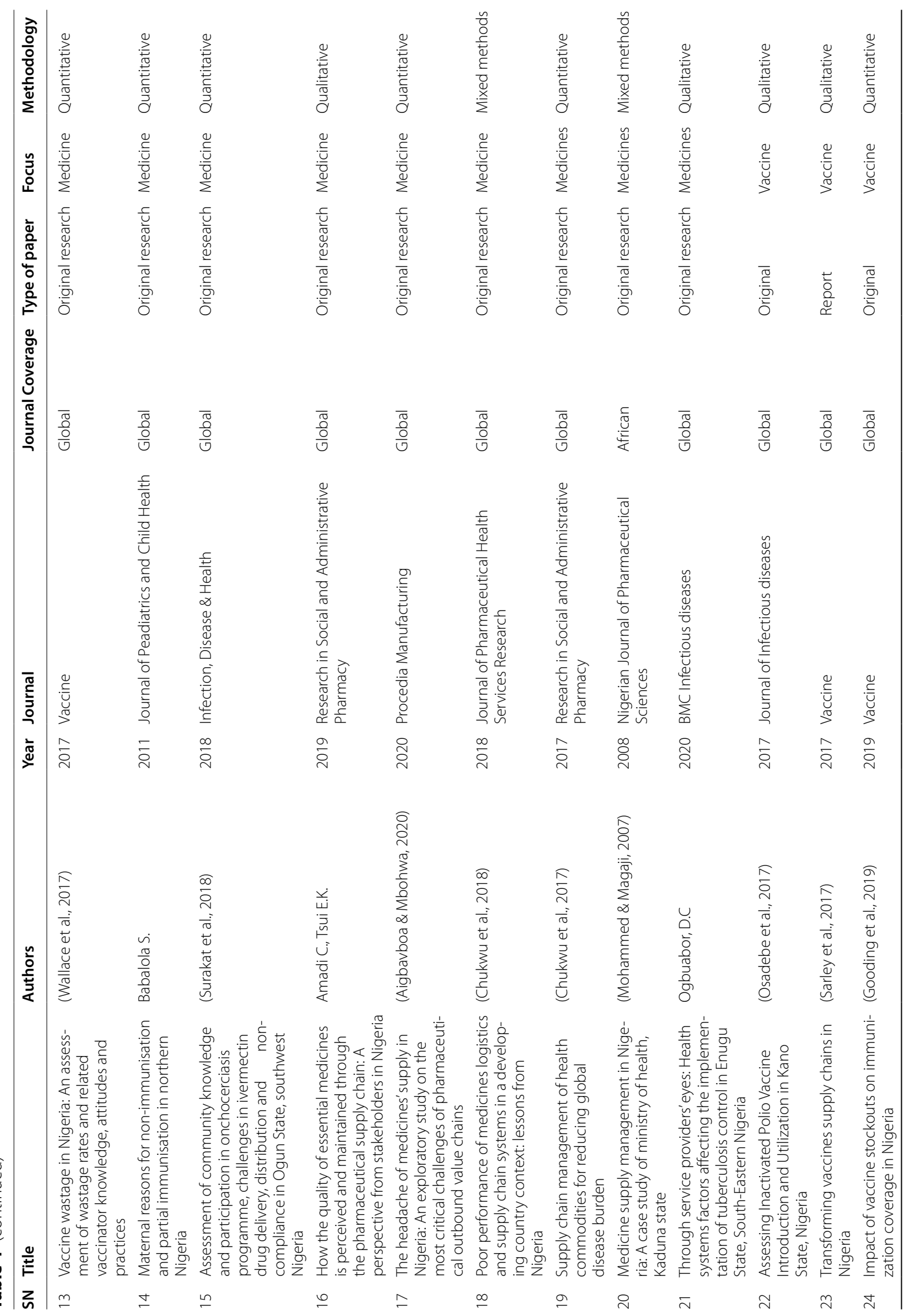




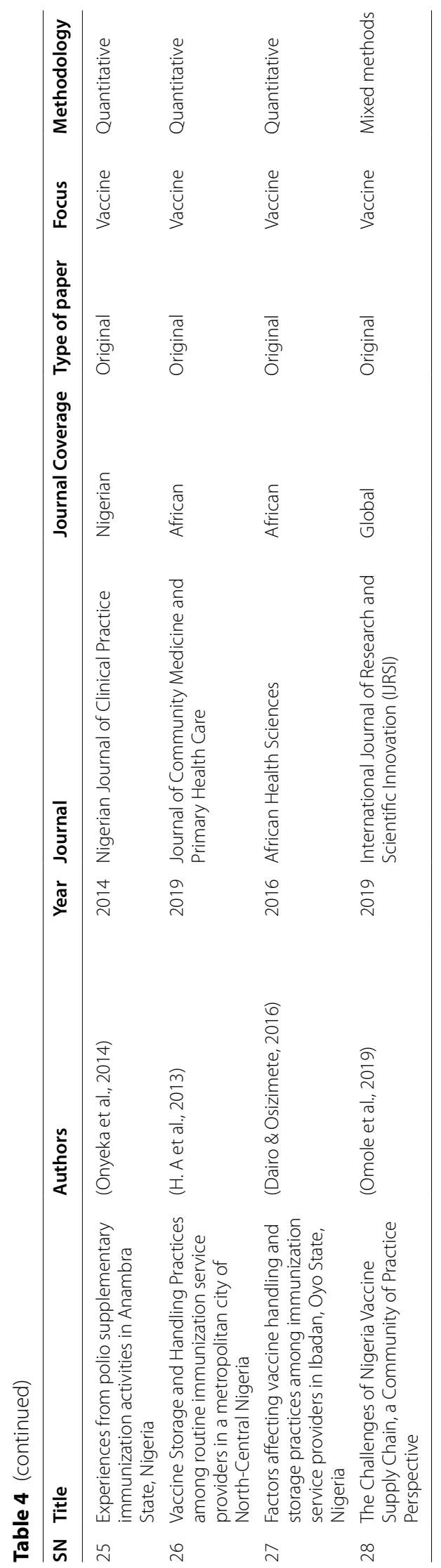




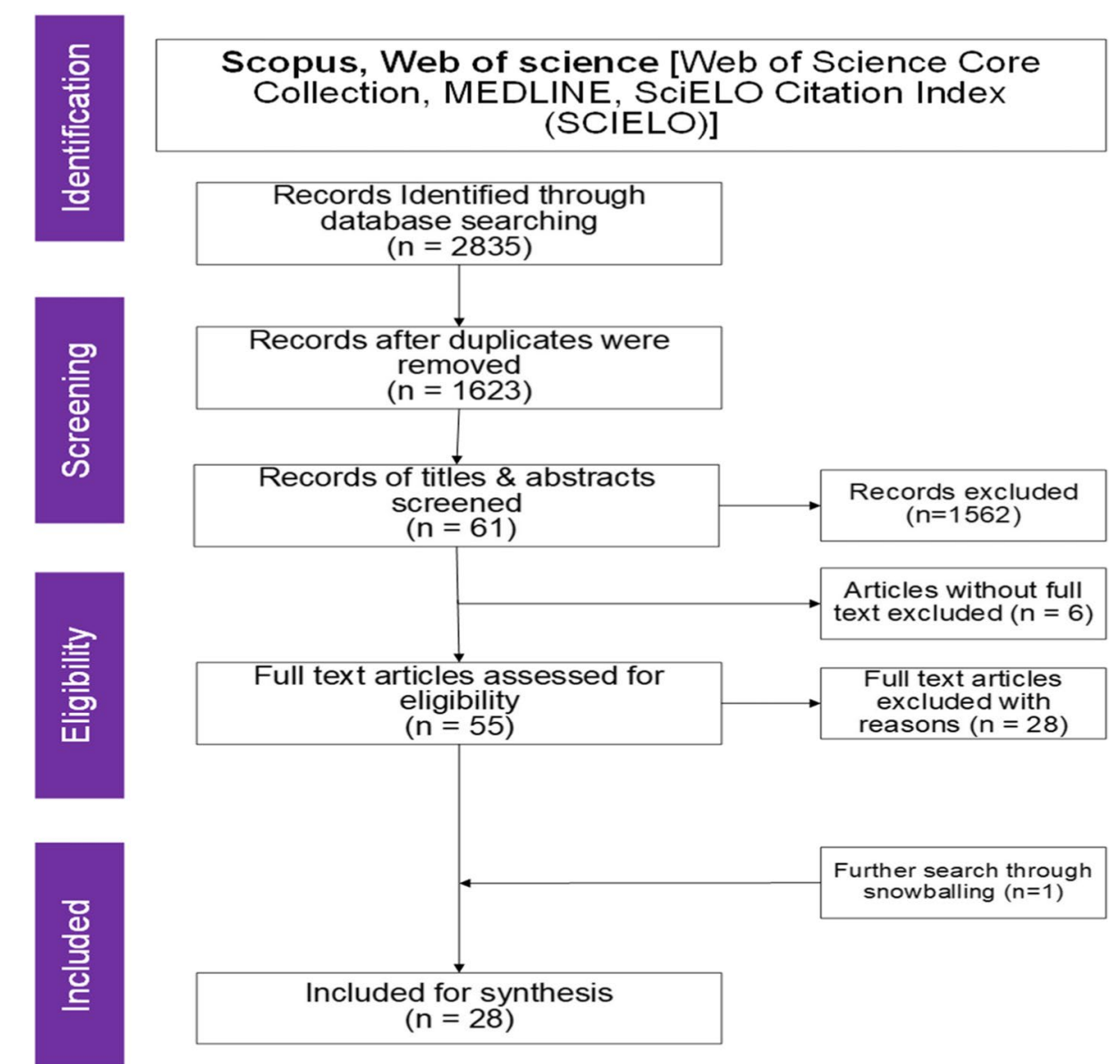

Fig. 1 PRISMA flowchart of the study selection process

Key findings, answering the scoping review question, are summarized in Table 7, and presented in the sub-sections below.

\section{Question: What are the challenges of medicines and vaccines supply chain in Nigeria?}

While medicine and vaccine supply chains are recognised, globally, as a key driver of access to medicines, evidence indicates that the system is often faced with many challenges. The objective of this scoping review was to summarize what is known about these challenges in Nigeria. In this review half of the studies (50\%) reported on the challenges confronting medicine supply chains, while the other half (50\%) reported the vaccine supply challenges in the country. The challenges were further categorized into themes as presented in Table 7.

\section{Human resource challenges}

Professionally, pharmacists play substantial roles in several aspects of medicine supply chains, yet not without challenges in aspects such as forecasting, procurement, inventory control, distribution and logistics management information system as reported by some authors [8]. Lack of support for personnel involved in medicine logistics and killing of personnel due to insurgency, inadequate personnel, lack of human resources, as well as corruption, were some of the medicine supply chain challenges identified in some states in Nigeria [2, 3, 8, 18]. In a study to evaluate access to immunization services in the Southern and Northern regions of Nigeria, inadequate human resources and vaccines were reported at service delivery points [19].

\section{Financial challenges}

An analysis of the expanded program on immunisation (EPI), indicated that there was poor coverage of the program due to shortage in vaccine supply and low funding for the program $[20,21]$. Furthermore, corruption 
Table 5 General characteristics of included scoping reviews $(n=28)$

\begin{tabular}{lll}
\hline Characteristic & Number & Percentage (\%) \\
\hline $\begin{array}{l}\text { Total number of included } \\
\text { articles }\end{array}$ & $\mathbf{2 8}$ & $\mathbf{1 0 0 \%}$ \\
$\begin{array}{l}\text { Publication year } \\
2005-2010\end{array}$ & \\
$2011-2015$ & 7 & $7 \%$ \\
$2016-2020$ & 19 & $25 \%$ \\
Journal coverage & & $68 \%$ \\
Nigerian & 1 & \\
African & 5 & $4 \%$ \\
Global & 22 & $18 \%$ \\
Focus of study & & $79 \%$ \\
Medicine & 14 & \\
Vaccine & 14 & $50 \%$ \\
Type of paper & & $50 \%$ \\
Original research & 25 & \\
Report & 2 & $89 \%$ \\
Review & 1 & $4 \%$ \\
Methodology & & $14 \%$ \\
Quantitative & 19 & $68 \%$ \\
Qualitative & 5 & $18 \%$ \\
Mixed method & 4 & \\
\hline
\end{tabular}

concerning funds meant for medicine supply, poor or inadequate funding, and lack of funds are some of the medicine and vaccine supply chain financial challenges, that have been reported by authors $[2,18,20,22,23]$.

\section{Delay, transportation, and distributions challenges}

Challenges related to delays in supply and operational logistics are commonly highlighted in studies [23-26]. For example, delay in importation and difficulty in maintaining the delivery vehicles in the supply of antimalarials were identified in a study in Nigeria [25]. Similarly, delay in the distribution of medicines for multi-drug resistant tuberculosis, due to delay in the submission of inventory reports, coupled with inaccurate reports and transportation challenges such as breakdown of vehicles were reported by some authors [24]. Inability to maintain optimum vaccine temperatures in delivery vehicles was also reported as a vaccine supply chain challenge in an evaluation of cold chain technology on measles vaccines [26]. A study reported the interruption of Tuberculosis (TB) drugs supply handled by logistics company, due to ineffective distribution of the medicines to the health facilities [27]. Insecurity during transportation of vaccines, inability to maintain the integrity of vaccines in the supply chain, and logistics distance between manufacturer and Nigeria were all identified as vaccine supply challenges in a recent study [23]. There are equally other challenges including damaged products and packages, unorganised supplies due to multiple distribution channels in the country which is associated with a high level of pilferage and loss on transit [2]

\section{Policy and standard operating procedure challenges}

Issues around poor policy or policy implementation rank among major challenges confronting the medicine supply chain system in Nigeria. A recent qualitative study, for example, highlighted the challenges posed by the lack of stringent policies or weak implementation of existing policies on the distribution and quality of medicines in the country [4]. Additional evidence implicates weak supply chain practices and a poor system of regulation $[2,3]$. Challenges such as poor procurement, incomplete forecasting, data collection and management, sub-optimal implementation of policies were further reported [2, 8]. It has been discovered that non-adherence to certain policies on vaccine administration led to excessive consumption exceeding supply which translated to Inactivated

Table 6 Frequency of articles reporting each challenge

\begin{tabular}{lll}
\hline Theme & $\begin{array}{c}\text { No of articles } \\
\text { Frequency of articles } \\
\text { reporting each } \\
\text { challenge }\end{array}$ \\
\hline Human resource challenges & 6 \\
Financial challenges & 5 & $14 \%$ \\
Transportation and distributions challenges & 5 & 5 \\
Policies and SOPs challenges & 5 & $11 \%$ \\
Storage challenges & 6 & $11 \%$ \\
Issues relating to medicines or vaccines stockouts & 6 & $14 \%$ \\
Technical issues & $18 \%$ \\
Poor data management of medicines and vaccines supply & $3 \%$ \\
\hline
\end{tabular}


Table 7 Summary of key findings from data synthesis

\begin{tabular}{|c|c|c|}
\hline Theme & Key findings & Studies \\
\hline Human resource challenges & $\begin{array}{l}\text { Challenges experienced by pharmacists with the } \\
\text { various aspects of the supply chain } \\
\text { Lack of support for personnel involved in medicine } \\
\text { logistics, inadequate personnel, lack of human } \\
\text { resources as well as corruption, killing of personnel } \\
\text { due to insurgency }\end{array}$ & $\begin{array}{l}\text { (Chukwu et al., 2018) (Eboreime et al., 2015) } \\
\text { (Chukwu et al., 2017) } \\
\text { (Mohammed \& Magaji, 2007) } \\
\text { (Aigbavboa \& Mbohwa, 2020) }\end{array}$ \\
\hline Financial challenges & $\begin{array}{l}\text { Lack of financial resources, Poor funding for vac- } \\
\text { cine supply }\end{array}$ & $\begin{array}{l}\text { (Mohammed \& Magaji, 2007) } \\
\text { (Chukwu et al., 2018) } \\
\text { (Sarley et al., 2017) } \\
\text { (Omole et al., 2019) } \\
\text { (Obioha et al., 2010) }\end{array}$ \\
\hline Delay, transportation and distributions challenges & $\begin{array}{l}\text { Delays in importation and difficulty in maintaining } \\
\text { delivery vehicles. Distribution challenge due to } \\
\text { delay in submission of inventory reports and sub- } \\
\text { mission of inaccurate inventory reports, insecurity } \\
\text { during transportation of vaccines and logistics dis- } \\
\text { tance between manufacturer and Nigeria. Inability } \\
\text { to monitor and maintain optimum temperatures } \\
\text { for vaccines during transportation }\end{array}$ & $\begin{array}{l}\text { (Palafox et al., 2014) } \\
\text { (Jatau et al., 2015) } \\
\text { (Omole et al., 2019) } \\
\text { (Oli et al., 2017) } \\
\text { (Ogbuabor, 2020) }\end{array}$ \\
\hline $\begin{array}{l}\text { Policies and Standard Operating Procedure (SOP) } \\
\text { challenges }\end{array}$ & $\begin{array}{l}\text { Inadequate implementation of medicine distribu- } \\
\text { tion policies, sub-optimal implementation of } \\
\text { policies, non-adherence to policies }\end{array}$ & $\begin{array}{l}\text { (Chukwu et al., 2017) } \\
\text { (Amadi \& Tsui, 2019) } \\
\text { (Chukwu et al., 2018) } \\
\text { (Scotney et al., 2017) }\end{array}$ \\
\hline Infrastructure and storage challenges & $\begin{array}{l}\text { Disruption of the supply chain through the } \\
\text { destruction of storage facilities, inadequate } \\
\text { storage facilities for ivermectin, inadequate cold } \\
\text { storage facilities, inadequate ice-packs }\end{array}$ & $\begin{array}{l}\text { (Aigbavboa \& Mbohwa, 2020) } \\
\text { (Surakat et al., 2018) } \\
\text { (Shittu et al., 2016) } \\
\text { (Ashok et al., 2017) } \\
\text { (Sarley et al., 2017) } \\
\text { (Ameen et al., 2013) }\end{array}$ \\
\hline Issues including medicines or vaccines stockouts & $\begin{array}{l}\text { Stock-outs, substandard medicines, shortage of } \\
\text { vaccine stock and vaccine stock-outs, Regular } \\
\text { stock-outs of essential medicines due to inefficient } \\
\text { inventory management systems, equipment and } \\
\text { corruption, Inadequate supply of vaccines }\end{array}$ & $\begin{array}{l}\text { (Aigbavboa \& Mbohwa, 2020) (Babalola 2011) } \\
\text { (Sato, 2019) } \\
\text { (Gooding et al., 2019) } \\
\text { (Chukwu et al., 2018) } \\
\text { (Obioha et al., 2010) } \\
\text { (Mohammed \& Magaji, 2007) } \\
\text { (Breakwell et al., 2017) }\end{array}$ \\
\hline Technical issues & $\begin{array}{l}\text { Interruption of drug supplies, Unreliable vaccine } \\
\text { supply, Inefficient procurement systems, Damaged } \\
\text { products and packages, loss of potency of cold } \\
\text { chain medical supplies, Irregular power supply } \\
\text { and use of archaic technology in vaccine handling, } \\
\text { inadequate ice blocks to maintain a cold chain }\end{array}$ & $\begin{array}{l}\text { (Breakwell et al., 2017) } \\
\text { (Ogbuabor, 2020) } \\
\text { (Babar et al., 2013) } \\
\text { (Dairo \& Osizimete, 2016) (Ashok et al., 2017) } \\
\text { (Onyeka et al., 2014) }\end{array}$ \\
\hline $\begin{array}{l}\text { Poor data management of medicines and vaccines } \\
\text { supply }\end{array}$ & $\begin{array}{l}\text { Poor procurement, incomplete forecasting, poor } \\
\text { data collection, use and management, Poor reli- } \\
\text { ability and availability of data for forecasting and } \\
\text { decision making, Sub-optimal data on vaccine } \\
\text { stock, Poor reliability and availability of data for } \\
\text { forecasting and decision making }\end{array}$ & $\begin{array}{l}\text { (Chukwu et al., 2018) } \\
\text { (Omole et al., 2019) } \\
\text { (Wallace et al., 2017) }\end{array}$ \\
\hline
\end{tabular}

Poliovirus Vaccine (IPV) stockout in Nigeria between March 2015 and June 2016 [28].

\section{Infrastructure and storage challenges}

Challenges bordering on infrastructure are equally highlighted in studies, for instance, in a survey among health workers, $62 \%$ of respondents mentioned inadequate storage facilities for medicines as one of the challenges encountered in the distribution of ivermectin [29]. Disruption of the supply chain through the destruction of storage facilities is similarly noted [3]. Substandard, inadequate vaccines storage facilities have also been identified especially in the local government areas of Nigeria [30]. Some of the challenges that affected cold chain performance were inadequate dry and cold chain storage facilities [22, 31]. A study on the storage practices of vaccines in a state in Nigeria reported that only $28.6 \%$ of the health facilities had functional thermometers in their stores [32]. 


\section{Issues including medicines or vaccines stockouts}

Other challenges commonly encountered include stockouts, substandard medicines, inadequate supply of vaccines, regular stock-outs of essential medicines due to inefficient inventory management systems [2, 3, 21, 33]. In a study on the impact of vaccine stockouts on the immunisation status of children, a lot of vaccine stockouts were reported [15]. Shortages and unreliable vaccine supply were reported as parts of the reasons for incomplete immunization and a barrier to immunisation uptake by children in some studies [20,33, 34]. Incomplete immunisation schedules due to an inadequate supply of vaccines have also been reported [18].

\section{Technical issues}

Suboptimal medicine infrastructure, substandard or use of archaic equipment in handling vaccines as well as poor monitoring of the required standard temperatures for the vaccines are among technical issues often encountered in the supply chains for medicines in
Nigeria [3, 31]. Inadequate ice packs to maintain optimum temperatures in the cold chain was reported as a challenge during a study on Polio immunization challenges [35]. Lack of stable power supply which leads to variability in temperatures of the vaccines has been reported as one of the challenges of vaccine supply management in Nigeria [36]. Another study in 52-lowmiddle income countries which includes Nigeria to determine the availability of asthma medications discovered inefficient procurement systems for the asthma medications in these countries [37] Irregular supply of vaccines has also been mentioned as one of the challenges encountered in Hepatitis B vaccination [34]. Poor equipment and corruption are part of the identified challenges associated with medicine supply chains in Nigeria [2, 3, 21, 33].

Poor data management of medicines and vaccines supply Poor data collection, quality and use of data were some of the vaccine supply chain challenges reported in a study

Table 8 Study Setting of included articles

\begin{tabular}{|c|c|}
\hline Authors & Study setting \\
\hline Palafox et al 2014 & Urban \\
\hline Sato 2019 & Setting is nationally representative \\
\hline Eboreime Ejemai, 2015 & Four states, two Northern and two Southern states \\
\hline Jatau et al,2015 & $\begin{array}{l}\text { Setting is nationally representative (All the seven } \\
\text { MDR-TB Centres in Nigeria) }\end{array}$ \\
\hline Babar et al, 2013 & Data is nationally representative \\
\hline Scotney et al, 2017 & Data is nationally representative \\
\hline Breakwell, 2017 & Data is nationally representative \\
\hline Oli et al, 2017 & South-East, Nigeria \\
\hline Tobin-West C.I.; Alex-Hart B.A., 2011 & Khana Local Government, Rivers State \\
\hline Obioha et al., 2010 & Data is nationally representative \\
\hline Ashok et al., 2017 & Data is nationally representative \\
\hline Wallace et al., 2017 & Data is nationally representative \\
\hline Babalola 2011 & Northern Nigeria \\
\hline Surakat et al., 2018 & Eight local government areas in Ogun State \\
\hline Amadi \& Tsui, 2019 & Four states, Enugu, Imo, lagos and Port-Harcourt \\
\hline Aigbavboa \& Mbohwa, 2020 & Data is nationally representative \\
\hline Chukwu et al., 2018 & Data is nationally representative \\
\hline Chukwu et al., 2017 & Abuja, Nigeria \\
\hline Mohammed \& Magaji, 2007 & Kaduna State \\
\hline Ogbuabor, 2020 & EnuguState \\
\hline Osadebe et al., 2017 & Kano State \\
\hline Sarley et al., 2017 & Data is nationally representative \\
\hline Gooding et al., 2019 & Data is nationally representative \\
\hline Onyeka et al., 2014 & Anambra State \\
\hline Ameen et al., 2013 & Two local Government areas in Kwara State, Nigeria \\
\hline Dairo \& Osizimete, 2016 & Eleven Local Government areas in Ibadan \\
\hline Omole et al., 2019 & The data is nationally representative \\
\hline
\end{tabular}


in Lagos state Nigeria [22]. Sub-optimal data on vaccine stock was also reported in a study on vaccine wastage in Nigeria [38]. Poor reliability and availability of data for forecasting and decision making were further reported [23].

\section{Rural-urban or regional differences}

Table 8 summarises settings (rural, urban, or mixed residence) where the reviewed studies were conducted in Nigeria. Notably, studies focused specifically on ruralurban differences in medicine and vaccine supply chain systems or those comparing one region with another (north vs south, for example), are limited. Many of the reviewed studies used data from multiple centres across the country (or population-based surveys) $[3,8,15,20$, $22-24,28,31,33,34,37,38]$, and thus, maybe nationally representative. We note that study settings (rural or urban) were rarely clearly described in many of the reviewed papers. Nonetheless, most of the data, including those from multiple centres, for example, the seven multi-drug resistant tuberculosis (MDR-TB) centres [24] were more likely to be from urban areas, and, thus, less likely to be nationally representative. This observation would mean some of the challenges reported in our study were probably underestimated as rural areas would normally be expected to experience even greater challenges associated with medicine and vaccine supply chain systems than urban centres in Nigeria. Where data from two or more local government areas (LGAs) were reported in the reviewed studies (Table 8), it may be expected that these cut across rural and urban areas in the respective states, since LGAs in Nigeria may have a mix of rural and urban centres. However, this is not necessarily the case in the present studies as some of the LGAs were indeed in urban settings, for example, the two LGAs studied in Kwara State (Ilorin East and Ilorin West) [32]. Overall, these findings suggest the need for future studies to prioritise rural-urban or regional differences in medicine and vaccine supply chain systems in Nigeria.

\section{Discussion}

This scoping review summarises the current body of knowledge on challenges associated with medicines and vaccines supply chain system in Nigeria. Our key findings implicate several challenges, particularly, those related to the key areas of medicines supply chain management in the country. Difficulty with medicine or vaccine selection, procurement, distribution, inventory management and storage infrastructure formed critical components of some of the challenges that mostly resulted in stock-outs of essential medicines in Nigeria. Challenges relating to medicines or vaccines stockouts were reported by the highest number of articles $(n=8)$, while challenges relating to poor data management of medicines and vaccines supply were only reported by three articles. Furthermore, financial constraints, poor information management and inadequate human resources were identified as parts of the challenges confronting the supply chains for medicines in the country.

Generally, our study found that frequent breakdown of vehicles coupled with poor road network system contributed to delay in the distribution of medicines in Nigeria and the finding is consistent with reports from other low-middle income countries such as Malawi [39]. This is, however, not the case in high-income countries such as the United States of America, where distribution challenges identified were more related to the lack of coordinated distribution of drug supplies especially during this present COVID-19 pandemic [40].

Challenges related to inefficient inventory control systems were consistently identified in several of the reviewed studies contributing largely to regular stockouts of medicines. This finding agrees with the results of a study on procurement challenges conducted in South Africa which similarly identified inefficient inventory control systems as parts of the factors contributing to shortages of medicines in the country [41]. Inadequate storage facilities, as well as an irregular power supply (necessary for maintaining cold chains vaccines), were common challenges reported in several articles reviewed in this study. These challenges could negatively impact the quality and efficacy of medicines and vaccines made available to patients. Our findings are consistent with those of an Ethiopian study which similarly reported inadequate storage facility and inability to maintain optimum temperature for the cold chain as parts of the challenges associated with medicines and vaccines supply chain system in the country [42]. Another study in Ethiopia also reported inadequate storage space for antiretroviral medicines and other HIV/AIDS-related products [43].

Weak policies, non-adherence and poor implementation of policies on medicines and vaccine supply identified in this review have also been identified in a systematic review on medicines management in India [44]. Insurgency has also been a major challenge identified in the medicines and vaccine supply chain in Nigeria and this was equally found in other countries around the world where insurgency have greatly impacted their healthcare delivery [45]. Other countries that reported a disruption in medicine and vaccine supplies were due to natural disasters and pandemics such as COVID-19 [40]. It is important to note that the challenges in Nigeria and other countries like Taiwan have been further 
complicated by the COVID-19 pandemic [46, 47]. Financial challenges, corruption and lack of human resources which are other challenges identified in this review have also been reported in Uganda [48].

\section{Conclusion/ Recommendations}

This study provides a summary of the challenges associated with supply chain systems for medicines and vaccines in Nigeria. Our findings revealed several challenges which contributed to frequent stockouts of essential medicines in the country. Stockouts would impact access to quality essential medicines thereby undermining efforts aimed at meeting one of the major targets of SDGs in Nigeria-access to safe, effective, quality, and affordable essential medicines and vaccines, for all. It is worth noting that the emergence of the COVID-19 global pandemic may have further complicated some of the challenges associated with medicines and vaccines supply chain in Nigeria. This suggests the need for creative context-specific approaches to addressing the challenges identified in our study. Moreover, our study highlights the need for more studies, especially, with regards to the ruralurban, or regional differences and in the context of the emergence of COVID-19 pandemic. Overall, the present study serves as a wake-up call to policymakers and regulators on the need to prioritise the critical sector of the supply chain system for medicines and vaccines in Nigeria. There is a need for effective strengthening of the system through adequate budgetary provision. Infrastructural development and regular availability of electricity supply are keys to the success of the supply chain system for medicines and vaccines in the country. Also, there is an urgent need for a deliberate effort aimed at effective implementation of relevant existing policies in the sector. This recommendation assumes greater importance given that a lack of stringent policy and weak implementation of existing policies were identified as major challenges in many of the reviewed studies.

\section{Acknowledgement \\ Special thanks to Dr Samuel O. Olutuase for the training on the use of Rayyan, a web-based systematic review software that was used in synthesizing the articles included in this study. We also appreciate his guide on the search strategy and methodology of this study.}

\section{Authors' Contributions}

VOO and CJl designed the study and drafted the manuscript. VOO, CJ, CPA, $\mathrm{EOA}$ and $\mathrm{VK}$ contributed to the analysis and interpretation of findings and revisions. All authors agreed on the final manuscript draft.

\section{Funding}

This research received no specific grant from any funding agency in the public, commercial or not-for-profit sectors.

\section{Availability of data and materials}

The datasets used and/or analysed during the current study are available from the corresponding author on reasonable request.

\section{Declaration}

Ethics approval and consent to participate Not applicable

\section{Consent for publication}

Not applicable.

\section{Competing interests}

None declared.

\section{Author details}

${ }^{1}$ Department of Clinical Pharmacy and Pharmacy Practice, University of Jos, Jos, Nigeria. ${ }^{2}$ Department of Nursing \& Midwifery, Faculty of Medicine and Health Sciences, Stellenbosch University, Stellenbosch, South Africa. ${ }^{3}$ Department of Nursing, Christian Service University College, Kumasi, Ghana. ${ }^{4}$ Collaborative Genomics and Translation Group, Centre for Precision Health, School of Medical and Health Sciences, Edith Cowan University, Joondalup, Western Australia 6027, Australia. ${ }^{5}$ Nepal Development Society, Butwal, Nepal.

Received: 23 May 2021 Accepted: 1 December 2021

Published online: 05 January 2022

\section{References}

1. United Nations Organisation. Transforming our world: The 2030 agenda for sustainable development. 2016.

2. Chukwu OA, Chukwu U, Lemoha C. Poor performance of medicines logistics and supply chain systems in a developing country context: lessons from Nigeria. J Pharm Heal Serv Res. 2018;9:289-91.

3. Aigbavboa S, Mbohwa C. The headache of medicines' supply in Nigeria: An exploratory study on the most critical challenges of pharmaceutical outbound value chains. In: Procedia Manufacturing. Elsevier B.V. 2020:336-43. https://doi.org/10.1016/j.promfg.2020.02.170.

4. Amadi C, Tsui EK. How the quality of essential medicines is perceived and maintained through the pharmaceutical supply chain: A perspective from stakeholders in Nigeria. Res Soc Adm Pharm. 2019;15:1344-57. https://doi.org/10.1016/j.sapharm.2018.11.011.

5. Ogbonna BO. National Drug Distribution in Nigeria ; Implications for the Goals of National National Drug Distribution in Nigeria ; Implications for the Goals. Eur J Pharm Med Res. 2016;3:1-4.

6. Yadav P. Health product supply chains in developing countries: Diagnosis of the root causes of underperformance and an agenda for reform. Heal Syst Reform. 2015;1:142-54.

7. Akinyandenu O. Counterfeit drugs in Nigeria: A threat to public health. African J Pharm Pharmacol. 2013;7:2571-6

8. Chukwu OA, Ezeanochikwa VN, Eya BE. Supply chain management of health commodities for reducing global disease burden. Res Soc Adm Pharm. 2017;13:871-4. https://doi.org/10.1016/j.sapharm.2016.08.008.

9. Fatokun O. Curbing the circulation of counterfeit medicines in Nigeria. Lancet. 2016;388:2603. https://doi.org/10.1016/S0140-6736(16)32121-3.

10. Maternal $\mathrm{N}$ and $\mathrm{CHP}(\mathrm{MNCH} 2)$. Improving reliability of drugs and medical supplies throough integrated supply chain management. 2016.

11. Hasan S, Wanyanga W. Pharmaceutical Sector Profile : Kenya Global UNIDO Project. Strengthening the local production of essential generic drugs in the least developed and developing countries. 2011.

12. Ogbonna BO, Ilika AL, Nwabueze S. National Drug Policy in Nigeria, 19852015. World J Pharm Res. 2015;4:248-64.

13. Peters M, Godfrey CM, Mcinerney P, Baldini Soares C, Khalil H, Parker D. 2017 Guidance for the Conduct of JBI Scoping Reviews. Joana Briggs Inst Rev Man. 2017;141-6. https://www.researchgate.net/publication/31971 3049_2017_Guidance_for_the_Conduct_of_JBI_Scoping_Reviews? enrichld =rgreq-2c63bf47a03bf1 c379fed09bf9a175b4-XXX\&enrichSour ce $=$ Y292ZXJQYWdIOzMxOTcxMzA0OTtBUzo1NDA5MDcxMjY4ODY0MD BAMTUwNTk3MzcxNjg4MA\%3D\%3D\&el=1_x_2\&. 
14. Peters MDJ, Godfrey CM, Khalil H, Mclnerney P, Parker D, Soares CB. Guidance for conducting systematic scoping reviews. Int J Evid Based Healthc 2015:13:141-6.

15. Gooding E, Spiliotopoulou E, Yadav P. Impact of vaccine stockouts on immunization coverage in Nigeria. Vaccine. 2019;37:5104-10. https://doi. org/10.1016/j.vaccine.2019.06.006.

16. Ouzzani M, Hammady H, Fedorowicz Z, Elmagarmid A. Rayyan - a web and mobile app for systematic reviews. Systematic Reviews. 2016;5.

17. Aromataris E, Munn Z, editors. JBI Manual for Evidence Synthesis. The Joanna Briggs Institute; 2020. doi:10.46658/JBIMES-20-01.

18. Mohammed S, Magaji MG, Lawal GS, Masoud MG. Medicine supply management in Nigeria : A case study of ministry of health. Kaduna State. Niger J Pharm Sci. 2007;6:116-20.

19. Eboreime E, Abimbola S, Bozzani F. Access to Routine Immunization : A Comparative Analysis of Supply-Side Disparities between Northern and Southern Nigeria. PLoS One. 2015:1-10.

20. Obioha EE, Ajala AS, Matobo TA. Analysis of the Performance of Expanded Programme on Immunization ( EPI ) for Four Child Killer Diseases under the Military and Civilian Regimes in Nigeria, 1995-1999; 2000- 2005 Ethno Med. 2010:4:43-52.

21. Babalola S. Maternal reasons for non-immunisation and partial immunisation in Maternal reasons for non-immunisation and partial immunisation in northern Nigeria. J Paediatr Child Health. 2011;47 September.

22. Sarley D, Mahmud M, Idris J, Osunkiyesi M, Dibosa-osadolor O, Okebukola P, et al. Transforming vaccines supply chains in Nigeria. Vaccine. 2017;35:2167-74. https://doi.org/10.1016/j.vaccine.2016.11.068.

23. Omole TM, Sanni FO, Olaiya PA, Aturaka O, Abdulsalam M, Gwa ZT, et al. The Challenges of Nigeria Vaccine Supply Chain, a Community of Practice Perspective. Int J Res Sci Innov. 2019;6:151-7.

24. Jatau B, Avong Y, Ogundahunsi O, Shah S, Smith KT, Van Den BR, et al. Procurement and Supply Management System for MDR-TB in Nigeria : Are the Early Warning Targets for Drug Stock Outs and Over Stock of Drugs Being Achieved? PLoS One. 2015;1-10.

25. Palafox B, Patouillard E, Tougher S, Goodman C, Hanson K, Kleinschmidt I, et al. Understanding Private Sector Antimalarial Distribution Chains : A Cross-Sectional Mixed Methods Study in Six Malaria-Endemic Countries. PLoS One. 2014;9

26. Oli AN, Agu RU, Ihekwereme CP, Esimone CO, Davis R, Cochi S, et al. An evaluation of the cold chain technology in South-East, Nigeria using Immunogenicity study on the measles vaccines. Pan Afr Med J. 2017;27(Supp 3):1-5.

27. Ogbuabor DC. Through service providers 'eyes : health systems factors affecting implementation of tuberculosis control in Enugu State. SouthEastern Nigeria. BMC Infect Dis. 2020;20:1-8

28. Scotney S, Snidal S, Saidu Y, Ojumu A, Ngatia A, Bagana M, et al. Succeeding in New Vaccine Introduction : Lessons Learned From the Introduction of Inactivated Poliovirus Vaccine in Cameroon, Kenya, and Nigeria. J Infect Dis. 2017;216(Suppl):1

29. Surakat OA, Sam S, Ademolu K, Adekunle MF, Adekunle ON, Monsuru AA, et al. Assessment of community knowledge and participation in onchocerciasis programme, challenges in ivermectin drug delivery, distribution and non - compliance in Ogun State. Southwest Nigeria. Infect Dis Heal. 2018:23:137-45

30. Shittu E, Harnly M, Whitaker S, Miller R. Reorganizing Nigeria's vaccine supply chain reduces need for additional storage facilities, but more storage is required. Health Aff. 2016;35:293-300.

31. Ashok A, Brison M, Letallec Y. Improving cold chain systems: Challenges and solutions. Vaccine. 2017;35:2217-23. https://doi.org/10.1016/j.vacci ne.2016.08.045

32. Ameen HA, A.G S, O.A B, M.M.B U, O.I M, S.A A. Vaccine Storage and Handling Practices among routine immunization service providers in a metropolitan city of North-Central Nigeria. J Community Med Prim Hea Care. 2013;26:18-28.

33. Sato R. Differential determinants and reasons for the non- and partial vaccination of children among Nigerian caregivers. Vaccine. 2019. https:// doi.org/10.1016/j.vaccine.2019.09.097.

34. Breakwell L, Tevi-benissan C, Childs L, Mihigo R, Tohme R. Review the status of hepatitis B control in the African region. Pan Afr Med J. 2017;27(Supp 3):1-11.
35. Onyeka IN, llika AL, llika FN, Umeh DC, Onyibe RI, Okoye CJ, et al. Experiences from polio supplementary immunization activities in Anambra State. Nigeria. Niger J Clin Pract. 2014;17:808-13.

36. Dairo DM, Osizimete OE. Factors affecting vaccine handling and storage practices among immunization service providers in Ibadan, Oyo State, Nigeria. Afr Health Sci. 2016;16.

37. Babar ZUD, Lessing C, Mace C, Bissell K. The availability, pricing and affordability of three essential asthma medicines in 52 low- and middleincome countries. Pharmacoeconomics. 2013:31:1063-82.

38. Wallace AS, Willis F, Nwaze E, Dieng B, Sipilanyambe N, Daniels D, et al. Vaccine wastage in Nigeria : An assessment of wastage rates and related vaccinator knowledge, attitudes and practices. Vaccine. 2017;35:6751-8.

39. Schouten EJ, Jahn A, Ben-Smith A, Makombe SD, Harries AD, AboagyeNyame F, et al. Antiretroviral drug supply challenges in the era of scaling up ART in Malawi. J Int AIDS Soc. 2011;14(SUPPL. 1):1-8.

40. Socal MP, Sharfstein JM, Greene JA. The Pandemic and the Supply Chain: Gaps in Pharmaceutical Production and Distribution. Am J Public Health. 2021;111:635-9.

41. Modisakeng C, Matlala M, Godman B, Meyer JC. Medicine shortages and challenges with the procurement process among public sector. BMC Health Serv Res. 2020;20:1-10.

42. Steve Hawkins, Gebre-Mariam T, Lassooy E. RPM+/SPS AND SCMS IN ETHIOPIA: AN EVALUATION. 2009.

43. Berhanemeskel E, Beedemariam G, Fenta TG. HIV/AIDS related commodities supply chain management in public health facilities of Addis Ababa, Ethiopia: A cross-sectional survey. J Pharm Policy Pract. 2016;9:1-10. https://doi.org/10.1186/s40545-016-0060-z.

44. Iqbal MJ, Geer MI, Dar PA. Medicines management in hospitals: A supply chain perspective. Syst Rev Pharm. 2016:8:80-5.

45. Malla S, Dumre SP, Shakya G, Kansakar P, Rai B, Hossain A, et al. The challenges and successes of implementing a sustainable antimicrobial resistance surveillance programme in Nepal. BMC Public Health. 2014;14:1-7.

46. Akande-Sholabi W, Adebisi YA. The impact of COVID-19 pandemic on medicine security in Africa: Nigeria as a case study. Pan Afr Med J. 2020;35(Supp 2):1-2.

47. Kuo S, Ou HT, Wang CJ. Managing medication supply chains: Lessons learned from Taiwan during the COVID-19 pandemic and preparedness planning for the future. J Am Pharm Assoc. 2021;61:e12-5. https://doi. org/10.1016/j.japh.2020.08.029.

48. Windisch R, Waiswa P, Neuhann F, Scheibe F, de Savigny D. Scaling up antiretroviral therapy in Uganda: Using supply chain management to appraise health systems strengthening. Global Health. 2011;7:1-11.

\section{Publisher's Note}

Springer Nature remains neutral with regard to jurisdictional claims in published maps and institutional affiliations.

Ready to submit your research? Choose BMC and benefit from

- fast, convenient online submission

- thorough peer review by experienced researchers in your field

- rapid publication on acceptance

- support for research data, including large and complex data types

- gold Open Access which fosters wider collaboration and increased citations

- maximum visibility for your research: over 100M website views per year

At BMC, research is always in progress.

Learn more biomedcentral.com/submissions 